\title{
THE COMPOSITE AORTIC WALL GRAFT TECHNIQUE: AN OPTION FOR A SHORT CORONARY ARTERY BYPASS GRAFT
}

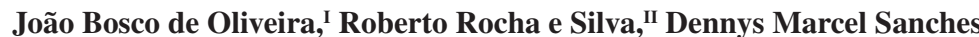

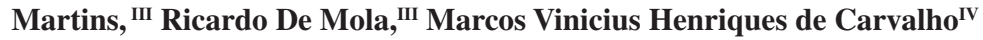

doi: $10.1590 / \mathrm{S} 1807-59322009000800017$

Oliveira JB, Rocha e Silva R, Martins DMS, Mola R, Carvalho MVH. The composite aortic wall graft technique: an option for a short coronary artery bypass graft. Clinics. 2009;64(8):815-8.

SUMMARY: During coronary artery bypass graft (CABG) surgery, the saphenous vein is sutured through its proximal segment to the aorta. Intimal hyperplasia is one of the possible causes of graft occlusion. Notably, blood turbulence can induce wall shear stress that may also play an important role in this process.

OBJECTIVE: We propose a new technique for performing proximal anastomosis to avoid CABG failure.

METHOD: An $80 \mathrm{~kg}$ pig was subjected to open heart surgery. Four stitches were placed in the anterior ascending aorta, which formed a $2 \mathrm{~cm}$ by $4 \mathrm{~cm}$ patch. This patch was isolated through the application of a tangential clamp that was oriented parallel to the axis of the aorta. After releasing the patch, which was held to the aorta through its cranial end pedicle, the rims were sutured to each other creating a conduit with a length of $4 \mathrm{~cm}$ and an internal diameter of $4 \mathrm{~mm}$. The rest of the aortotomy was closed by placing a direct suture between its rims.

RESULT: This novel technique created an "in situ" aortic wall graft that was $4 \mathrm{~cm}$ long and characterized as being of uniform 4 mm caliber.

KEYWORDS: Coronary artery bypass; Anastomosis; surgical; Aorta; Myocardial revascularization.

\section{INTRODUCTION}

Coronary artery bypass graft $(\mathrm{CABG})$ using the left internal thoracic artery (LITA) to the left anterior descending artery (LADA) is the gold standard for multivessel coronary disease procedures. The second graft is usually implanted with its proximal segment to the aorta. However, approximately $20 \%$ of the saphenous veins present some degree of stenosis during the first year after surgery. ${ }^{1}$ Recent studies have demonstrated that wall shear stress is maximized at the proximal anastomosis, probably due to

\footnotetext{
I Hospital Beneficência Portuguesa, Cardiologia - São Paulo/SP, Brazil "Cardiac Surgery, INCOR, Hospital das Clínicas da Faculdade de Medicina da Universidade de São Paulo - São Paulo/SP, Brazil

III Hospital e Maternidade Paulo Sacramento - Jundiaí/ SP, Brazil

${ }^{\mathrm{IV}}$ Faculdade de Medicina de Jundiaí - Jundiaí/ SP, Brazil

E-mail: fmj@fmj.br

Tel: 55114587.1095

Received for publication on May 22, 2009

Accepted for publication on May 28, 2009
}

turbulence. ${ }^{2,3}$ This elevated wall shear stress may be related to the occurrence of intimal hyperplasia that leads to late graft failure..$^{4-6}$

In order to avoid graft failure, we propose a new technique for performing the proximal anastomosis procedure such that the high wall shear stress will be localized at an "in situ" aortic wall graft that may exhibit improved pressure tolerance. Our approach may help avoid proximal intimal hyperplasia.

\section{MATERIAL AND METHODS}

This research was approved by the Ethics Committee of the Jundiaí School of Medicine. An $80 \mathrm{~kg}$ pig was subjected to general anesthesia with mechanical ventilation. Access to the heart was through sternotomy and pericardial opening. Four stitches were placed in the anterior ascending aorta to create a $2 \mathrm{~cm}$ by $4 \mathrm{~cm}$ patch (Figure 1A). This patch was isolated using a tangential clamp that was positioned 
parallel to the axis of the aorta (Figure 1B). After releasing the patch, which was held to the aorta through its cranial end pedicle (Figures 1C and 1D), the rims of the patch were sutured to each other, creating a conduit of length 4 $\mathrm{cm}$ and with an internal diameter of $4 \mathrm{~mm}$ (Figure 1E). The rest of the aortotomy was closed by applying a direct suture between it's rims. In addition, a PTFE tube that simulated a saphenous conduit was sutured to the distal end of the conduit (Figure 1F).

Results. This technique resulted in the creation of a proximal aortic wall graft $4 \mathrm{~cm}$ long with an internal diameter of $4 \mathrm{~mm}$. This graft possessed a distal end with an opening similar to the usual aortic site for proximal anastomosis (Figure 2). The graft exhibited sufficient mobility and was appropriate for either the right or left coronary arteries. The graft allowed for the implantation of the composite graft without further aortic clamping.
In our experimental model, a PTFE tube was implanted towards the distal end of the aortic graft (simulating a saphenous graft) in order to create a composite graft with a homogenous diameter (Figure 3).

\section{DISCUSSION}

The aortic wall graft is an easy technique to perform because once the aortic patch is obtained, both conduit creation and the aortic closure only require linear sutures.

During standard anastomosis, the high wall shear stresses associated with the proximal anastomosis may lead to intimal hyperplasia and graft failure. ${ }^{3,6}$ With this proposed technique, the high wall shear stress will be localized to the "in situ" aortic wall graft. This may offer better pressure tolerance and will thus be better equipped to avoid intimal hyperplasia.
A

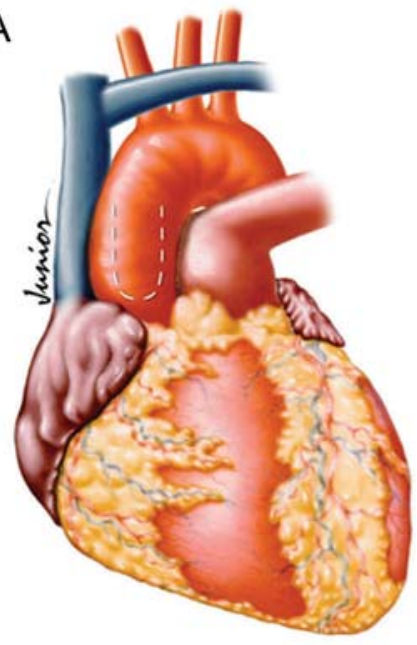

D

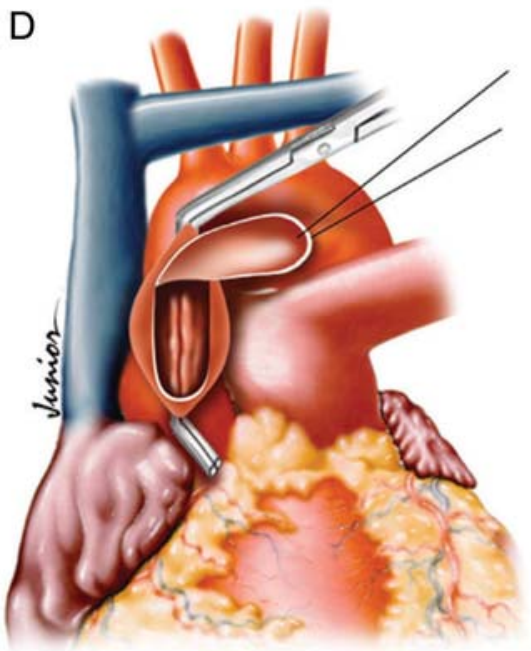

B

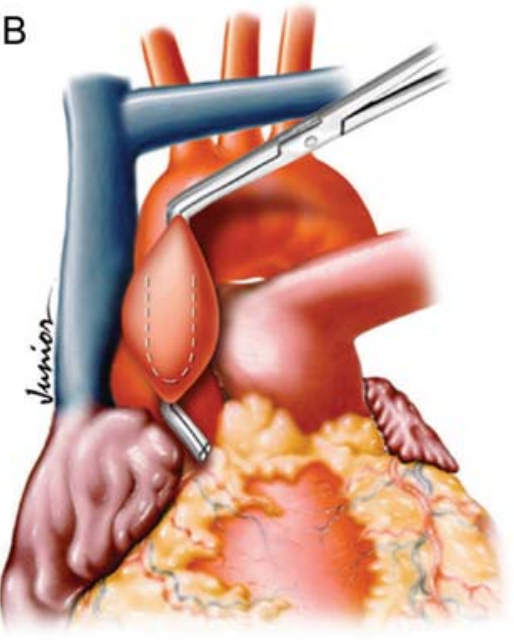

E

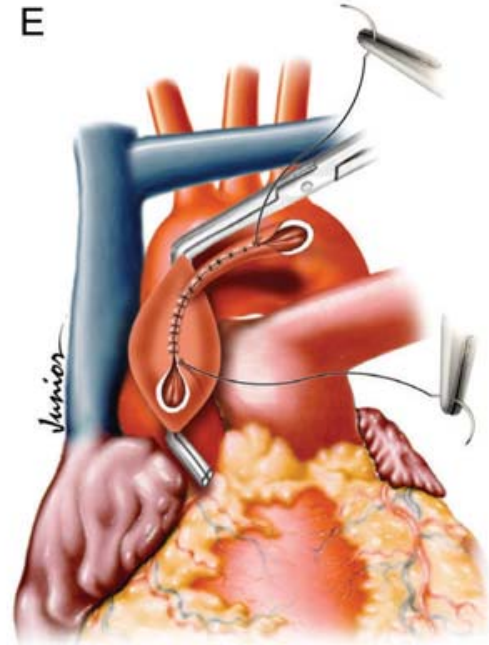

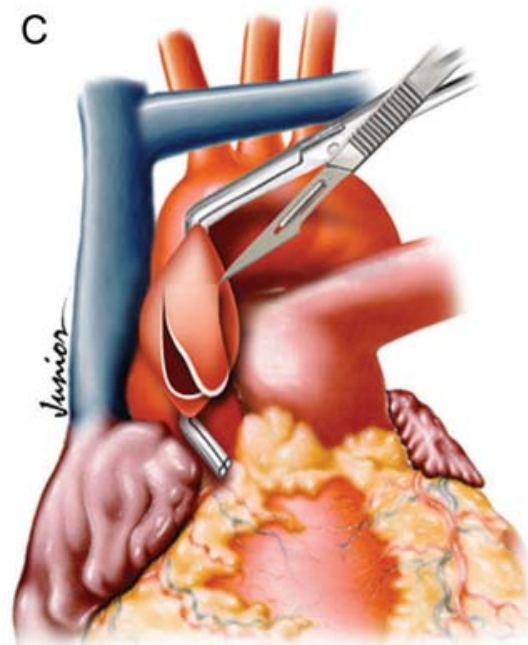

F

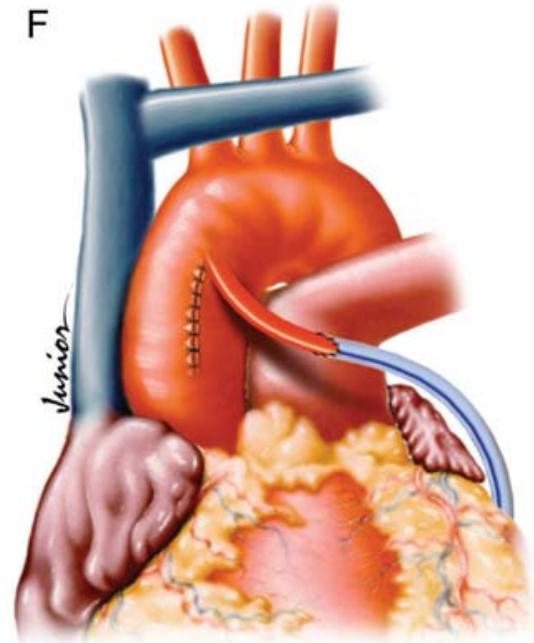

Figure 1 (A-F) - Schematic representation of surgical steps 


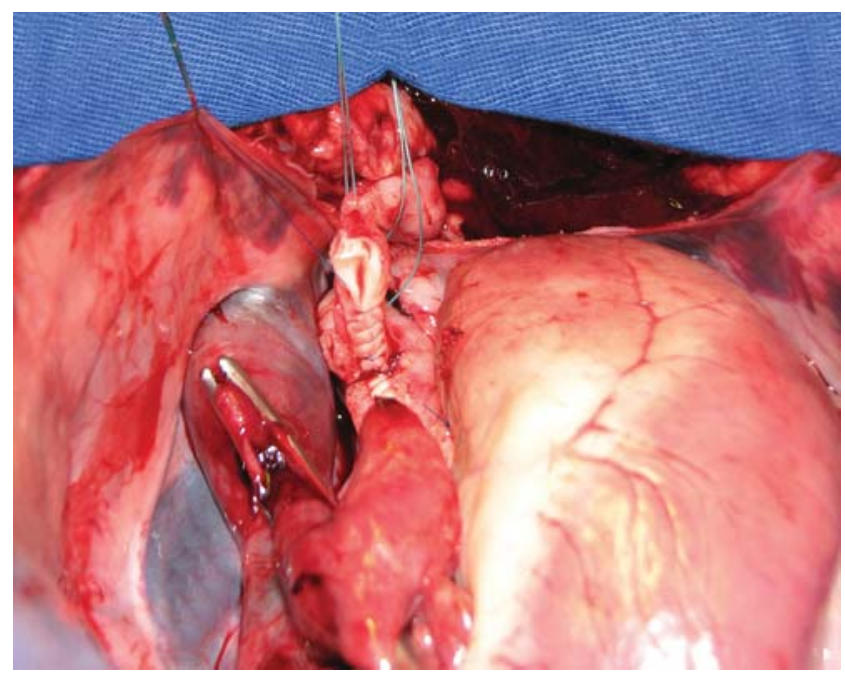

Figure 2 - Distal end of graft, ready for anastomosis with bridging vessel

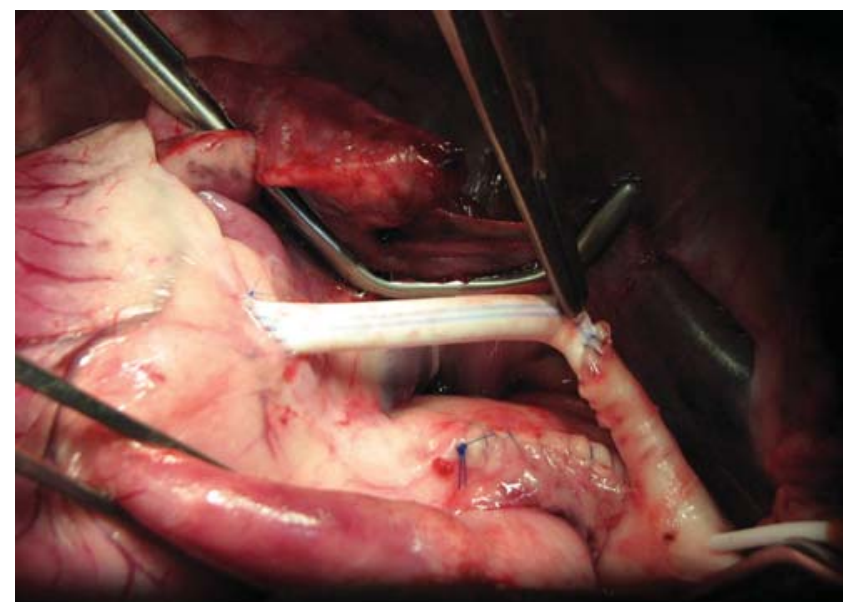

Figure 3 - PTFE tube implanted in the distal end of the aortic graft (simulating a saphenous graft) resulting in a composite graft with a homogenous diameter
Because the composite graft to be implanted in the end of the aortic graft will be of similar diameter, there will be little turbulence and consequently low wall shear stress. We expect that intimal hyperplasia would be unlikely to occur under these conditions.

Several studies have demonstrated the benefits of complete arterial revascularization..$^{7-11}$ This technique can add an additional $4 \mathrm{~cm}$ to a radial artery graft, which in turn allows it to reach the circumflex and the right coronary regions through sequential anastomosis. In addition, this should not increase the chances of morbidity because the aortic manipulation consists of a couple of linear sutures.

The potential benefits of this technique include a possible reduction in the graft failure rate due to intimal hyperplasia, which avoids the recurrence of symptoms and future operations.

In some cases, where the patient presents with some limitation in the graft (previous bilateral saphenectomy, redo $\mathrm{CABG}$, or low quality saphenous graft), this technique may allow for a complete revascularization of the surgical area. Moreover, in circumstances when the graft size is underestimated, this technique can overcome the problem.

\section{CONCLUSION}

To the best of our knowledge, this technique has never been described. Our results suggest that it allows for a proximal "in situ" aortic wall graft of excellent quality. Further work is required to determine its safety and reliability. As described above, this procedure appears to be a simple and straightforward approach that adds an extra 4 $\mathrm{cm}$ onto the composite graft.

\section{REFERENCES}

1. Guthaner DF, Robert EW, Alderman EL, Wexler L. Long-term serial angiographic studies after coronary artery bypass surgery. Circulation. 1979;60:250-9.

2. Sankaranarayanan M, Ghista DN, Chua LP, Tan YS, and Kassab GS. Analysis of blood flow in an out-of-plane CABG model. Am J Physiol Heart Circ Physiol 291:H283-H295,2006.

3. Sankaranarayanan M, Chua LP, Ghista DN, and Tan YS. Computational model of blood flow in the aorto-coronary bypass graft (Abstract). Biomed Eng Online 4:14,2005.
4. Imparato AM, Bracco A, Kim GE, Zeff R. Intimal and neointimal fibrous proliferation causing failure of arterial reconstructions. Surgery. 1972;72:1007-17.

5. Nikkari ST, Clowes AW. Restenosis after vascular reconstruction. Ann Med. 1994;26:95-100.

6. Clowe, AW. Pathologic intimal hyperplasia as a response to vascular injury and reconstruction. In: Rutherford RB. , editor. Vascular Surgery. 4. Philadelphia: WB Saunders Company; 1995. pp. 285-95. 
7. Rocha-e-Silva R, Santos TS, Rochite CE, Rocha-Filho JA, Mansur AP, Fabri J Jr, Ramos RB, Dallan LA, Stolf NA. Elective vs non-elective radial artery grafts: comparing midterm results through 64-Slice computed tomography. Clinics. 2007;62:725-30.

8. Rocha-E-Silva R, de Pádua Mansur A, Fabri Junior J, Ramos RB, Cunha Filho CE, Dallan LA, de Oliveira SA. Coronary revascularization with the left internal thoracic artery and radial artery: comparison of shortterm clinical evolution between elective and emergency surgery. Clinics. 2005;60:227-32.
9. Oliveira JB, Rocha-e-Silva R, De Mola R, Pantoja RAR. Radial artery harvesting technique without hemostatic clips and clinical experience. Rev Bras Cir Cardiovasc. 2008;23:114-7.

10. Zacharias A, Schwann TA, Riordan CJ, Durham SJ, Shah AS, Habib $\mathrm{RH}$. Late results of conventional versus all-arterial revascularization based on internal thoracic and radial artery grafting. Ann Thorac Surg. 2009;87:19-26.

11. Rocha-e-Silva R, Truffa MA, Birolli JRBM, Silva TF, De Mola R, Oliveira JB. Análise angiográfica tardia dos enxertos empregados na revascularização miocárdica de pacientes com retorno de sintomas. Rev Bras Cir Cardiovasc. 2009;24:138-42. 